\title{
Mechanism of the effect of tanshinone IIA epithelial-mesenchymal transition via the TGF- $\beta 1 /$ smad pathway in human alveolar epithelial cell line A549.
}

\author{
Bai-Yan Wang ${ }^{1}$, Yan Jin², Cai-Li Zhang ${ }^{2}$, Jun-Xia Zhang², Li-Min Sun², Ying-Ke Guo², Rui-Qin Li2* \\ ${ }^{1}$ Key Discipline Laboratory of Basic Medicine, Henan University of Traditional Chinese Medicine, PR China \\ ${ }^{2}$ Scientific Research Pathological Experiment Center, Henan University of Traditional Chinese Medicine, Zhengzhou, \\ PR China
}

\begin{abstract}
This study aimed to investigate the inhibitory effects of the different concentrations of Tanshinone IIA (Tan IIA) on the proliferation of human alveolar epithelial cell line A549 and its regulatory mechanism in epithelial-mesenchymal transition (EMT). The proliferation activity of cells was examined using the thiazolyl blue tetrazolium bromide (MTT) method. The changes in the expression of epithelial cell marker protein E-cadherin (E-cad) and interstitial marker protein alpha-smooth muscle actin ( $\alpha$-SMA) were detected using the cellular immunochemical method. The changes in cell morphology and ultrastructure were observed under the inverted microscope and transmission electron microscope, respectively. Western blot analysis was used to detect the expression of E-cad, $\alpha$-SMA, Smad7, and Smad3. The MTT assay showed that the cell viability in the transforming growth factor beta 1 (TGF- $\beta 1$ ) induced group was higher than that in the normal group, but the difference was not obvious. However, the cell viability of the Tan IIA-treated groups obviously decreased compared with the TGF- $\beta 1$-induced and normal groups. Meanwhile, the expression of E-cad and $S \operatorname{mad} 7$ decreased, and the expression of $\alpha$ SMA and Smad3 increased after A549 cells were induced by $5 \mathrm{ng} / \mathrm{mL}$ TGF- $\beta 1$ for $24 \mathrm{~h}$. However, their expression levels were close to the expression level of the control group after the cells were treated with Tan IIA for $24 \mathrm{~h}$. In conclusion, the results demonstrated that Tan IIA could inhibit EMT of alveolar epithelial cells induced by TGF- $\beta 1$, probably by regulating the expression of TGF- $\beta /$ Smad pathway protein. Therefore, Tan IIA might serve as a potential anti-fibrosis drug in treating pulmonary fibrosis.
\end{abstract}

Keywords: EMT, Pulmonary fibrosis, Tan IIA, TGF- $\beta 1 /$ Smad.

Accepted on May 08, 2018

\section{Introduction}

Air pollution has become highly harmful to human health in recent years. Pulmonary Fibrosis (PF) is a common chronic progressive respiratory disease in today's society. PF represents a group of devastating and largely irreversible disorders characterized by badly damaged airway, secretion of inflammatory factors, epithelial-mesenchymal transition (EMT), apoptosis, oxidative stress, proliferation of lung fibroblasts, and extracellular matrix over-accumulation [1-3]. EMT refers to the gradual disappearance of epithelial cells and their transformation into mesenchymal cells with migration and invasive ability $[4,5]$. At present, EMT is considered as an important mechanism for the development of $\mathrm{PF}$; the transforming growth factor beta 1 (TGF- $\beta 1$ )/Smad signal transduction pathway also plays an important role. This may provide guidance for preventing and treating PF [6-12]. However, no direct evidence is available regarding the relationship between TGF- $\beta 1 /$ Smad and EMT during lung fibrosis.
Salvia miltiorrhiza is a well-known herb in traditional Chinese medicine reported to promote blood circulation and prevent blood stasis. Tanshinone is an effective extract of $S$. miltiorrhiza. Tanshinone IIA (Tan IIA) is a kind of monomer with anti-oxidative, anti-inflammatory, anti-tumor, and antiatherosclerotic effects [13]. Some recent studies demonstrated that Tan IIA could inhibit fibrosis in various tissues and organs via intrinsic and extrinsic pathways [14,15]. These studies demonstrated that Tan IIA could inhibit fibrosis by downregulating the expression of TGF- $\beta 1$ and $\alpha$-SMA and partially blocking the TGF- $\beta 1 /$ Smad signaling pathway. However, the relationship between TGF- $31 /$ Smad and EMT still remains unclear. Meanwhile, few studies were conducted on the molecular mechanism of Tan IIA inhibiting EMT in PF. The aim of this study was to investigate the intervention mechanism of Tan IIA in preventing and treating PF. It was found that Tan IIA alleviated PF by inhibiting TGF- $\beta / \mathrm{Smad}$ signaling pathways and EMT in A549 cells stimulated by TGF- $\beta 1$. 


\section{Materials and Methods}

\section{Drugs and reagents}

Human recombinant TGF- $\beta 1$ was purchased from PeproTech Company (NJ, USA). Tan IIA was purchased from Shanghai Biochemical Company (Shanghai, China). Osmic acid, lead, and uranium were obtained from TedPella Inc, CA, and USA. Rabbit anti-human polyclonal antibody to E-cad, Smad3/7, mouse anti-human monoclonal antibody to $\alpha$-SMA, and goat anti-rabbit and mouse secondary antibody kit were all supplied by Boster Biological Technology, Ltd, Wuhan, China.

\section{Instruments}

The instruments used in the study included inverted phase contrast microscope (Olympus, Japan), microplate reader (Thermo, MA, USA), ultrathin slicing machine and semiautomatic rotary slicer (Leica company, Germany), and transmission electron microscope (JEM-1400, JEOL, Japan).

\section{Cell culture and grouping}

The human alveolar epithelial cell line A549 was provided by KeyGen Biotechnology Co., Ltd (Nanjing, China), and grown in RPMI 1640 medium (Beijing Solarbio Science \& Technology Co., Ltd., China) supplemented with $10 \%$ fetal bovine serum (Gibco, NY, USA), and the cells were incubated at $37^{\circ} \mathrm{C}$ in a humidified atmosphere with $5 \% \mathrm{CO}_{2}$. The study comprised normal control group, TGF- $\beta 1$-induced group, and groups treated with different doses of Tan IIA. The normal control group was treated with the same volumes of culture medium, and the TGF- $\beta 1$-induced group was treated with 5 $\mathrm{ng} / \mathrm{mL}$ TGF- $\beta 1$ for $24 \mathrm{~h}[16,17]$. In the groups treated with different doses of Tan IIA, A549 cells were stimulated first with $5 \mathrm{ng} / \mathrm{mL}$ TGF- $\beta 1$ for $24 \mathrm{~h}$ and then different concentrations of Tan IIA $(50,100,150 \mu \mathrm{g} / \mathrm{mL})$ were added to the corresponding groups.

Table 1. Effects of Tan IIA on the proliferation of A549 cells $(n=3, \bar{x} \pm s)$.

\begin{tabular}{|c|c|c|c|c|}
\hline Group & $12 \mathrm{~h}$ & $24 \mathrm{~h}$ & $36 \mathrm{~h}$ & $48 \mathrm{~h}$ \\
\hline Normal control group & $0.540 \pm 0.006$ & $0.596 \pm 0.015$ & $0.685 \pm 0.042$ & $0.776 \pm 0.022$ \\
\hline TGF- $\beta 1$-induced group & $0.563 \pm 0.010^{*}$ & $0.596 \pm 0.001^{*}$ & $0.703 \pm 0.005^{*}$ & $0.822 \pm 0.020^{*}$ \\
\hline Tan IIA, $50 \mu \mathrm{g} / \mathrm{mL}$ & $0.492 \pm 0.013^{\#}$ & $0.530 \pm 0.011^{\#}$ & $0.609 \pm 0.009^{\#}$ & $0.659 \pm 0.014^{\#}$ \\
\hline Tan IIA, $100 \mu \mathrm{g} / \mathrm{mL}$ & $0.439 \pm 0.010^{\#}$ & $0.472 \pm 0.008^{\#}$ & $0.578 \pm 0.009^{\#}$ & $0.609 \pm 0.009^{\#}$ \\
\hline Tan IIA, $150 \mu \mathrm{g} / \mathrm{mL}$ & $0.404 \pm 0.004^{\#}$ & $0.445 \pm 0.006^{\#}$ & $0.518 \pm 0.022^{\#}$ & $0.537 \pm 0.025^{\#}$ \\
\hline
\end{tabular}

Compared with the normal control group, ${ }^{*} \mathrm{P}>0.05$; compared with the TGF- $\beta 1$-induced group, ${ }^{\#} \mathrm{P}<0.05$.

\section{MTT to detect the inhibitory effect of Tan IIA on A549 cells}

The cells in the logarithmic growth phase were collected and kept in 96-well plates with $5 \times 10^{3}$ cells/well. Each group included six wells, four time points $(12,24,36$, and $48 \mathrm{~h})$, and three plates at each time point. The cells adhered to the wall for $24 \mathrm{~h}$, the old medium was discarded, and different concentrations of Tan IIA were added to the corresponding groups. After incubating the cells for 12, 24, 36, and $48 \mathrm{~h}, 20$ $\mu \mathrm{L}$ of MTT (Sigma, USA) was added to each well for $4 \mathrm{~h}$. Then, $150 \mu \mathrm{L}$ of dimethyl sulfoxide/well was added to the cells and shaken for $20 \mathrm{~min}$. The experiment was repeated three times. The growth curve of A549 cells was plotted according to the optical density value at $490 \mathrm{~nm}$.

\section{Morphological changes in cells under an inverted microscope}

The morphological changes in A549 cells induced by TGF- $\beta 1$ and treated with Tan IIA for $24 \mathrm{~h}$, compared with the control group, were observed using an inverted microscope. The roundness and radius ratio of cells were calculated referring to a quantitative analysis method. The roundness is perimeter $2 /(4$ $\times \pi \times$ area). The radius ratio is a ratio between long axis and short axis [18].

\section{Ultrastructural changes in cells under a transmission electron microscope}

For transmission electron microscopy analysis, the cells were fixed in $4 \%$ cold glutaraldehyde at $4{ }^{\circ} \mathrm{C}$ for $4 \mathrm{~h}$, collected, and centrifuged for $5 \mathrm{~min}$ (1000 rpm). Then, they were rinsed with phosphate-buffered saline (PBS), fixed with $1 \%$ osmium tetroxide for $1.5 \mathrm{~h}$, dehydrated, and embedded in epoxy resin $\left(37^{\circ} \mathrm{C}\right.$ for $12 \mathrm{~h}, 45^{\circ} \mathrm{C}$ for $12 \mathrm{~h}$, and $60^{\circ} \mathrm{C}$ for $24-48 \mathrm{~h}$ ). Ultrathin sections were double stained with lead citrate for $5 \mathrm{~min}$ and uranyl acetate for $25 \mathrm{~min}$ and then examined under a JEM-1400 transmission electron microscope at the magnification of $12,000 \mathrm{X}$.

\section{Expressions of E-cad and $\alpha-S M A$ detected by cell immunochemistry}

The cells were fixed with $4 \%$ paraformaldehyde at room temperature for $30 \mathrm{~min}$ and stained according to the immunocytochemical kit instructions. The presence of brown particles in the cytoplasm or on the cell membrane was regarded as positive expression. All images were analyzed 
using image analysis software (Image-Pro Plus7.0, Media Cybernetics, MD, USA), and the integrated optical density (IOD) of positive cells was calculated.

\section{Expressions of E-cad, $\alpha-S M A$, Smad7, and Smad3 analyzed by Western blot}

The cells cultured for $24 \mathrm{~h}$ were rinsed twice with ice-cold PBS and harvested. The total protein of cells was extracted, and its concentration was determined using the bicinchoninic acid method. Samples containing equal amounts of proteins $(25 \mu \mathrm{g})$ were loaded and analyzed by Western blot. Briefly, the proteins were separated by $12 \%$ sodium dodecyl sulfate-polyacrylamide gel electrophoresis (SDS-PAGE) and transferred onto a polyvinylidene fluoride membrane. The membrane was rinsed with Tris-buffered saline Tween 20 (TBST, $20 \mathrm{mM}$ Tris- $\mathrm{HCl}$, $\mathrm{pH} 7.6,150 \mathrm{mM} \mathrm{NaCl}$, and $0.05 \%$ Tween 20) for $5 \mathrm{~min}$, incubated with blocking buffer $\left(5 \%\right.$ non-fat dry milk at $4{ }^{\circ} \mathrm{C}$ overnight or for at least $1 \mathrm{~h}$ at room temperature), and then incubated with appropriate primary antibodies (1:2000) on a shaker at room temperature for 2-4 $\mathrm{h}$. The membrane was washed with TBST five times ( 6 min each time), followed by incubation with horseradish peroxidase-linked secondary antibody (1:2000) at room temperature for $1 \mathrm{~h}$. After the membranes were washed again under the same conditions, all protein bands were detected using the chemiluminescence detection system.

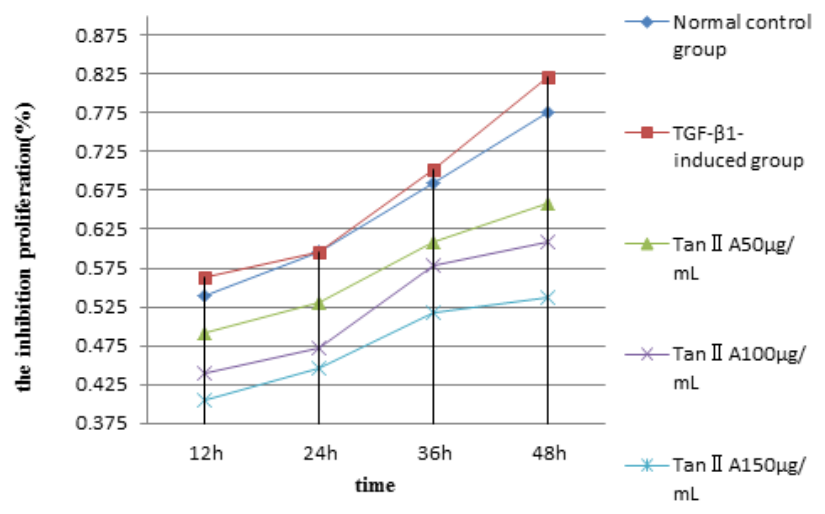

Figure 1. Effects of Tan IIA on the proliferation of A549 cells.

\section{Statistical analysis}

SPSS17.0 software package was used for data analysis. The datum consistent with the normal distribution was described with the mean \pm standard deviation and statistically compared using the one-way analysis of variance test. Significance was defined as $\mathrm{P}<0.05$.

\section{Results}

\section{Effect of Tan IIA on the proliferation of A549 cells}

The MTT method was used to assess whether different concentrations of Tan IIA had an inhibitory effect on the proliferation of A549 cells. The results showed that the proliferative activity of A549 cells increased in the TGF- $\beta 1$ induced group, but the difference was not significant compared with the normal control group $(\mathrm{P}>0.05)$. However, the proliferation of cells treated with different concentrations of Tan IIA for 12-48 $\mathrm{h}$ was suppressed obviously (Table 1). Meanwhile, the inhibition rate gradually decreased with the administration of Tan IIA dose $(50-150 \mu \mathrm{g} / \mathrm{mL})$. On the contrary, the inhibition rate gradually increased with the extension of time (12-48 h) at the same dose. It demonstrated that the growth of cells was obviously inhibited in both doseand time-dependent manners $(\mathrm{P}<0.05)$ (Figure 1).

\section{Morphological changes in cells were observed under an inverted microscope}

The A549 cells in the control group were found to be circular, polygonal, or cobble shaped under an inverted microscope. The cells were closely connected. When A549 cells were induced by TGF- $\beta 1$ for $24 \mathrm{~h}$, the cell morphology changed into long spindle-shaped cells. However, the morphological changes in cells treated with Tan IIA were gradually close to those in the normal control group. The cells became shorter, were rounder than those in the TGF- $\beta 1$-induced group, and even restored the cobble shape. On the contrary, the reduction in cell number indicated that Tan IIA could inhibit the proliferation of cells (Figure 2). The quantitative analysis results show the roundness and radius ratio of cells in TGF- $\beta 1$ induced group had statistical significance $(\mathrm{P}<0.05)$ compared with the normal control group. Moreover, the difference between Tan IIA-treated and TGF- $\beta 1$-induced groups was also statistically significant $(\mathrm{P}<0.05)$ (Figure 3$)$. The radius ratio measurement for Tan IIA treatment group shows concentration dependence, however the roundness measurement does not exhibit such a trend. This may be related to the random selection of interest areas in the analysis.
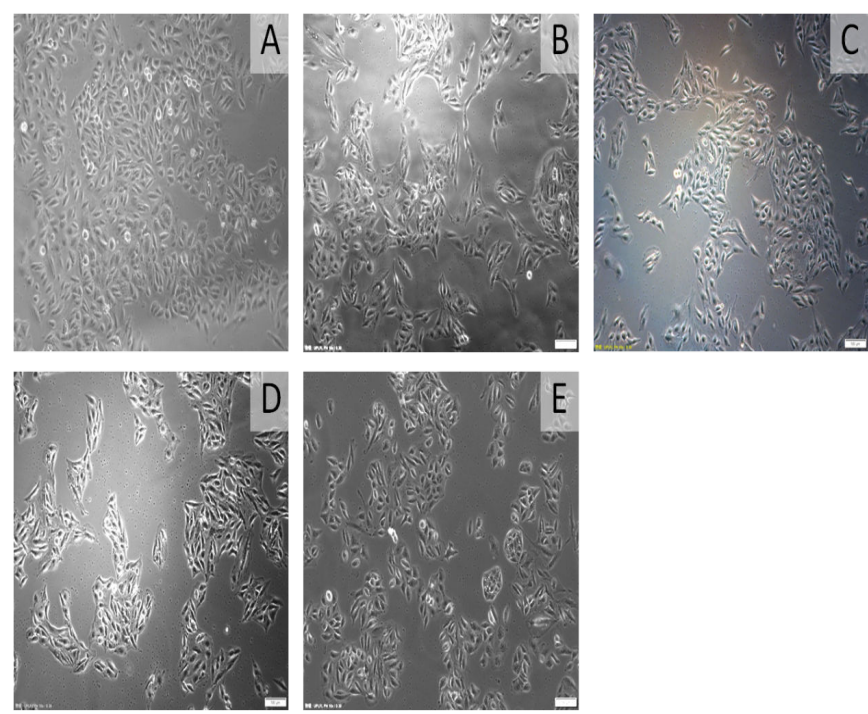

Figure 2. Comparison of cell morphology of A549 cells treated with different concentrations of Tan IIA and TGF- $\beta 1$ for $24 \mathrm{~h}$ examined under an inverted microscope (100X). (A) Normal control group; (B) $5 \mathrm{ng} / \mathrm{mL}$ TGF- $\beta 1$-induced group; (C) $50 \mu \mathrm{g} / \mathrm{mL}$ Tan IIA group; (D) $100 \mu \mathrm{g} / \mathrm{mL}$ Tan IIA group; (E) $150 \mu \mathrm{g} / \mathrm{mL}$ Tan IIA group. 

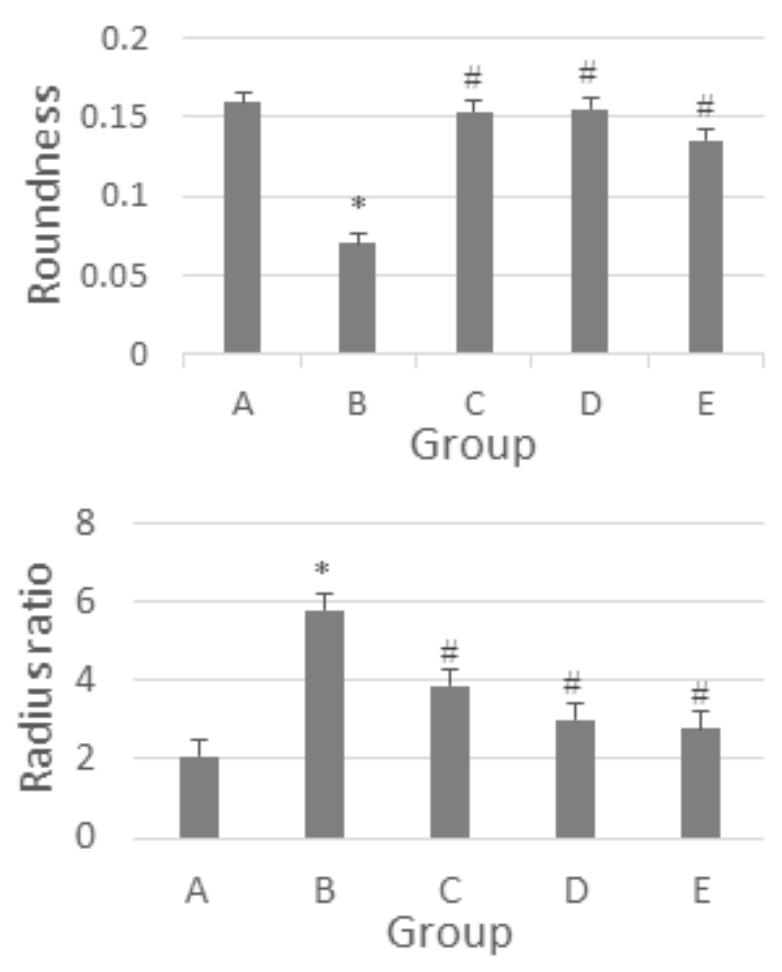

Figure 3. Effects of Tan IIA on the roundness and radius ratio of A549 cells. (A) Normal control group; (B) $5 \mathrm{ng} / \mathrm{mL} T G F-\beta 1$-induced group; (C) $50 \mu \mathrm{g} / \mathrm{mL}$ Tan IIA group; (D) $100 \mu \mathrm{g} / \mathrm{mL}$ Tan IIA group; (E) $150 \mu \mathrm{g} / \mathrm{mL}$ Tan IIA group. Compared with the normal control group, $* P<0.05 ;$ compared with the TGF- $\beta 1$-induced group, ${ }^{\#} P<0.05$.

\section{Ultrastructural changes in the cells were observed under a transmission electron microscope}

The ultrastructural changes in A549 cells induced by TGF- $\beta 1$ and treated with Tan IIA were observed using a transmission electron microscope (Figure 4). The A549 cells in the normal control group were characterized by clearly visible lamellar bodies (also known as osmium bodies; lamellar or concentric) and many villi on the cell surface (Figure 4A). The ultrastructural changes in the cells in the TGF- $\beta 1$-induced group included degeneration and swelling of lamellar bodies, vacuolization in the cytoplasm, shrinkage and fragmentation of the nucleus, decreased number of microvilli, increased rough endoplasmic reticulum, and expansion of mitochondria (Figure 4B). Interestingly, the lamellar body and surface microvilli increased obviously in the cells treated with Tan IIA for $24 \mathrm{~h}$ compared with the TGF- $\beta 1$-induced group.

\section{Expressions of E-cad and $\alpha-S M A$ detected by cell immunochemistry}

The epithelial marker protein E-cad was mainly expressed in the cell membrane and partially in the cytoplasm in the normal control group; the interstitial cell marker $\alpha$-SMA was mainly expressed in the cytoplasm. The expression of E-cad in the A549 cells in the TGF- $\beta 1$ induced group significantly decreased compared with the normal control group. However, the expression of $\alpha$-SMA significantly increased. Many brown granules were uniformly distributed in the cytoplasm. The IOD values of E-cad and $\alpha$-SMA were detected using Image-Pro Plus7.0 (Media Cybernetics). The expression of E-cad and $\alpha$ SMA in the TGF- $\beta 1$ induced group had statistical significance $(\mathrm{P}<0.05)$ compared with the control group, as shown in Table 2 and Figure 5.

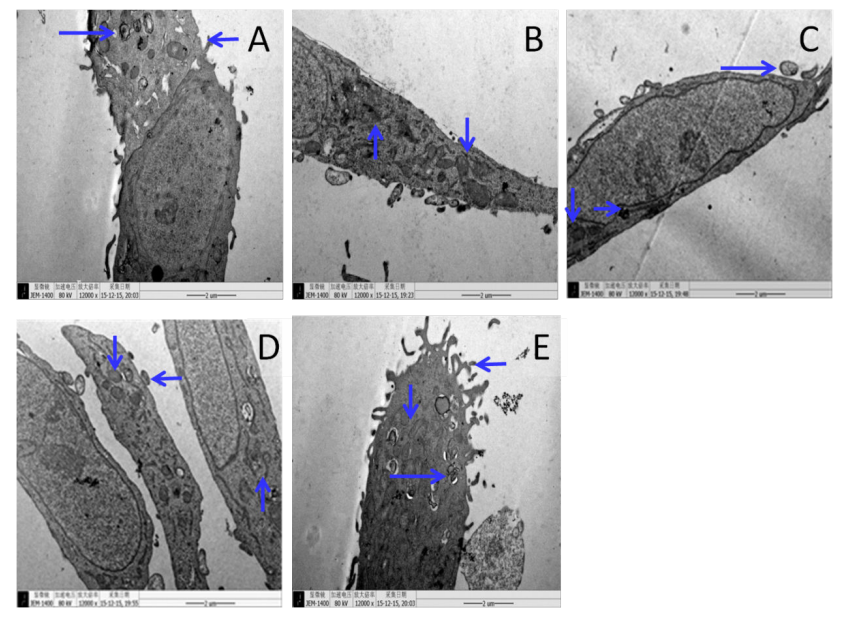

Figure 4. Representative transmission electron microscope images of the ultrastructure of cells (lead and uranium double staining, 12,000X). (A) Normal control group; (B) $5 \mathrm{ng} / \mathrm{mL} T G F-\beta 1$-induced group; (C) $50 \mu \mathrm{g} / \mathrm{mL}$ Tan IIA group; (D) $100 \mu \mathrm{g} / \mathrm{mL}$ Tan IIA group; (E) $150 \mu \mathrm{g} / \mathrm{mL}$ Tan IIA group. Lamellar bodies $(\rightarrow)$, microvilli $(\leftarrow)$, mitochondria $(\downarrow)$, rough endoplasmic reticulum $(\uparrow)$.

Table 2. Expression of E-cad and $\alpha$-SMA in cells induced by TGF- $\beta 1$ for $24 h(x \pm s)$.

\begin{tabular}{lcll}
\hline Group & N & E-cad & a-SMA \\
\hline Normal control group & 5 & $35.950 \pm 1.836$ & $11.404 \pm 0.995$ \\
\hline TGF- $\beta 1$-induced group & 5 & $3.319 \pm 0.241^{*}$ & $48.318 \pm 1.819^{*}$ \\
\hline Compared with the normal control group, ${ }^{*} \mathrm{P}<0.05$. &
\end{tabular}

\section{Expressions of E-cad, $\alpha-S M A$, Smad7, and Smad3 analyzed by Western blot}

Western blot was performed to analyze the proteins associated with fibrosis to characterize the molecular changes in Tan IIAtreated A549 cells. The expression of epithelial cell marker protein E-cad decreased, whereas the expression of interstitial cell marker $\alpha$-SMA increased $(\mathrm{P}<0.05)$ when the A549 cells were treated with TGF- $\beta 15 \mathrm{ng} / \mathrm{mL}$ for $24 \mathrm{~h}$, compared with the normal control group (Table 3 and Figure 6). The expression of proteins was close to that in the normal control group after the intervention of Tan IIA for $24 \mathrm{~h}$, with a doseeffect relationship. The difference between the experimental and normal control groups was statistically significant $(\mathrm{P}<0.05)$. Moreover, the difference between Tan IIA-treated and TGF- $\beta 1$-induced groups was also statistically significant $(\mathrm{P}<0.05)$. Meanwhile, the expression of signaling pathway protein $\mathrm{Smad} 7$ in A549 cells induced by $5 \mathrm{ng} / \mathrm{mL}$ TGF- $\beta 1$ for $24 \mathrm{~h}$ decreased, but the expression of $\operatorname{Smad} 3$ increased 
$(\mathrm{P}<0.05)$, compared with the normal control group. The expression level of protein was similar to that in the normal control group after the intervention of Tan IIA for $24 \mathrm{~h}$. The difference between the experimental and normal control groups was statistically significant $(\mathrm{P}<0.05)$. Moreover, the difference between Tan IIA-treated and TGF- $\beta 1$-induced groups was also statistically significant $(\mathrm{P}<0.05)$ (Table 4 and Figure 7).
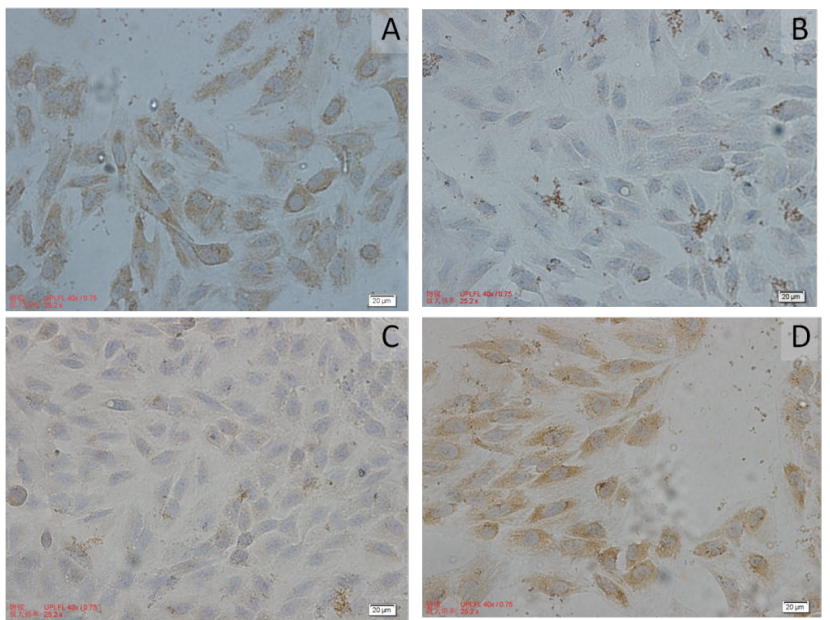

Figure 5. Expression of E-cad and $\alpha-S M A$ was detected by cell immunochemistry after the cells were induced by $5 \mathrm{ng} / \mathrm{mL}$ TGF- $\beta 1$ for $24 \mathrm{~h}$ (400X). (A) Expression of E-cad in the normal control group; (B) expression of E-cad in the TGF- $\beta 1$-induced group; (C) expression of $\alpha-S M A$ in the normal control group; (D) expression of $\alpha-S M A$ in the TGF- $\beta 1$ induced group.

Table 3. Expression of E-cad and $\alpha-S M A$ in cells induced by TGF- $\beta 1$ and treated with Tan IIA for $24 h(\bar{x} \pm s)$.

\begin{tabular}{lcll}
\hline Group & N & E-cad & a-SMA \\
\hline Normal control group & 3 & $0.647 \pm 0.009$ & $0.395 \pm 0.010$ \\
\hline TGF- $\beta 1$-induced group & 3 & $0.378 \pm 0.004^{*}$ & $0.717 \pm 0.006^{*}$ \\
\hline Tan IIA, $50 \mu \mathrm{g} / \mathrm{mL}$ & 3 & $0.435 \pm 0.006^{* \#}$ & $0.677 \pm 0.011^{* \#}$ \\
\hline Tan IIA, $100 \mu \mathrm{g} / \mathrm{mL}$ & 3 & $0.520 \pm 0.007^{* \#}$ & $0.566 \pm 0.010^{* \#}$ \\
\hline Tan IIA, $150 \mu \mathrm{g} / \mathrm{mL}$ & 3 & $0.574 \pm 0.010^{* \#}$ & $0.449 \pm 0.028^{* \#}$ \\
\hline
\end{tabular}

Compared with the normal control group, ${ }^{*} \mathrm{P}<0.05$; compared with the TGF- $\beta 1$ induced group, ${ }^{\#} \mathrm{P}<0.05$.

\section{Discussion}

S. miltiorrhiza, also known as Dan-shen in Chinese, is a typical herb known for promoting blood circulation and detumescence, cooling blood, nourishing blood, and regulating menstrual function [19]. It comprises both fat-soluble and water-soluble components. Tanshinone is a fat-soluble abietane-type diterpenoid compound and is mainly extracted from the root of S. miltiorrhiza. As one of the effective extraction monomers, Tan IIA has a wide range of pharmacological actions. Many studies have shown that Tan IIA plays a key role in scavenging oxygen free radicals, protecting nerves, and exerting antiatherosclerosis, anti-tumor, and anti-fibrosis effects [20,21]. The present study found that the morphology of A549 cells stimulated by $5 \mathrm{ng} / \mathrm{mL}$ TGF- $\beta 1$ for $24 \mathrm{~h}$ obviously changed. The cells were significantly elongated and spindle shaped similar to fibroblasts, with an extended gap between cells. However, the shape of the cells in the normal control group was polygonal and paving stone-like. At the same time, transmission electron microscopy showed osmiophilic lamellar body degeneration, swelling, vacuolar changes, reduction in the number of microvilli, increase in rough endoplasmic reticulum, mitochondrial swelling, and increase in euchromatin. This indicated EMT in A549 cells induced by TGF- $\beta 1$ for $24 \mathrm{~h}$.

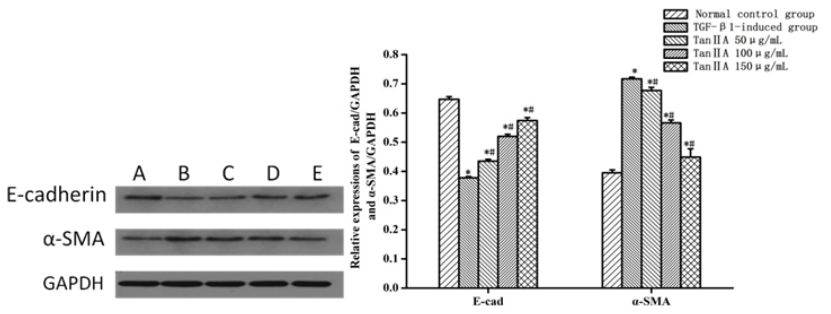

Figure 6. Western blot was used to detect the expression of E-cad and $\alpha-S M A$ in A549 cells treated with Tan IIA for $24 h$. (A) Normal control group; (B) $5 \mathrm{ng} / \mathrm{mL}$ TGF- $\beta 1$-induced group; (C) $50 \mu \mathrm{g} / \mathrm{mL}$ Tan IIA group; (D) $100 \mu \mathrm{g} / \mathrm{mL}$ Tan IIA group; (E) $150 \mu \mathrm{g} / \mathrm{mL}$ Tan IIA group.

Table 4. Expression of Smad3 and Smad7 in cells induced by TGF- $\beta 1$ and treated with Tan IIA for $24 h(\bar{x} \pm s)$.

\begin{tabular}{lcll}
\hline Group & N & Smad3 & Smad7 \\
\hline Normal control group & 3 & $0.308 \pm 0.010$ & $0.626 \pm 0.012$ \\
\hline TGF- $\beta 1$-induced group & 3 & $0.620 \pm 0.018^{*}$ & $0.355 \pm 0.011^{*}$ \\
\hline Tan IIA, $50 \mu \mathrm{g} / \mathrm{mL}$ & 3 & $0.562 \pm 0.038^{* \#}$ & $0.408 \pm 0.010^{* \#}$ \\
\hline Tan IIA, $100 \mu \mathrm{g} / \mathrm{mL}$ & 3 & $0.537 \pm 0.019^{* \#}$ & $0.440 \pm 0.010^{* \#}$ \\
\hline Tan IIA, $150 \mu \mathrm{g} / \mathrm{mL}$ & 3 & $0.430 \pm 0.014^{* \#}$ & $0.486 \pm 0.012^{* \#}$ \\
\hline
\end{tabular}

Compared with the blank control group, ${ }^{*} \mathrm{P}<0.05$; compared with the TGF- $\beta 1$ induced group, ${ }^{\#} \mathrm{P}<0.05$.

The occurrence of EMT is associated with a variety of molecular changes, such as the activation of transcription factors, reconstruction and expression of cytoskeleton protein, and expression of specific cell surface proteins including E-cad and $\alpha$-SMA. E-cad is a transmembrane protein of epithelial cells and one of the important components of cell-to-cell tight junctions, which ensures the integrity and polarity of epithelial cells [22]. As a component of cytoskeleton, $\alpha$-SMA is expressed by myofibroblasts, which are a heterogeneous population of highly profibrogenic cells; high levels indicate the progression of fibrosis with collagen deposition. In experimental studies on fibrosis, this interstitial marker is highly expressed a few days after induction of fibrosis $[23,24]$. Hence, E-cad and $\alpha$-SMA are emerging as one of the hallmarks of EMT. The expression of E-cad decreased, and the expression of $\alpha$-SMA increased in the present study. The content of E-cad decreased initially, the close connection between cells was destroyed, the adhesion between alveolar 
epithelial cells was lost, and new phenotypic proteins such as $\alpha$-SMA were expressed in the cytoplasm during the transformation of A549 cells induced by TGF- $\beta 1$ into stromal cells. The expression of E-cad significantly decreased, and the expression of $\alpha$-SMA significantly increased after A549 cells were induced by TGF- $\beta 1$ for $24 \mathrm{~h}$ in the cellular immunochemical experiment. This result also supported the transformation of alveolar epithelial cells into interstitial cells after the cells were induced by TGF- $\beta 1$ for $24 \mathrm{~h}$.

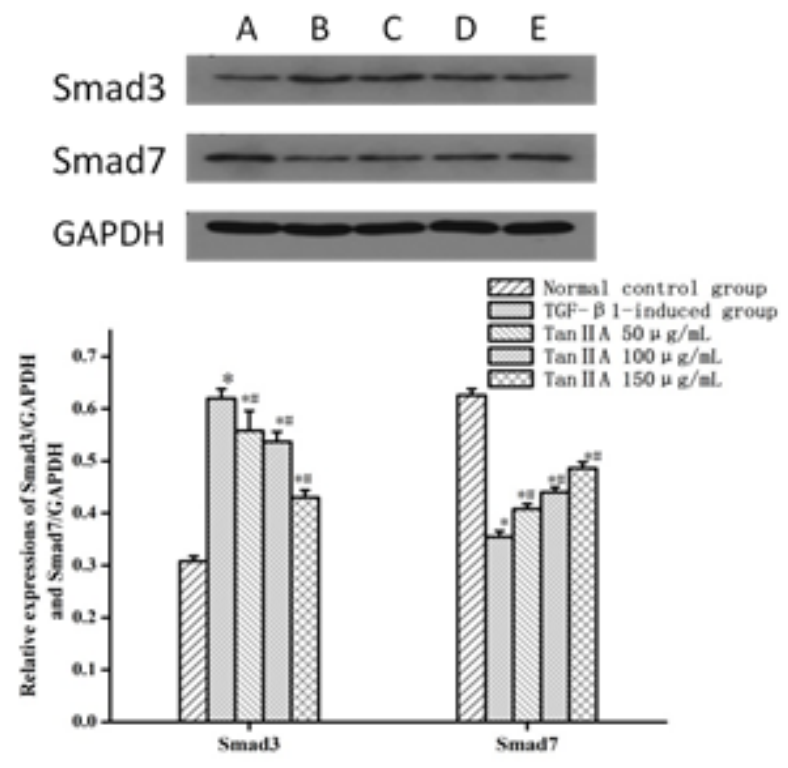

Figure 7. Western blot was used to detect the expression of Smad3 and Smad7 in A549 cells treated with Tan IIA for 24 h. (A) Normal control group; (B) $5 \mathrm{ng} / \mathrm{mL}$ TGF- $\beta 1$-induced group; (C) $50 \mu \mathrm{g} / \mathrm{mL}$ Tan IIA group; (D) $100 \mu \mathrm{g} / \mathrm{mL}$ Tan IIA group; (E) $150 \mu \mathrm{g} / \mathrm{mL}$ Tan IIA group.

EMT is triggered by multiple extracellular stimuli. Of these extracellular cues, TGF- $\beta 1$ has a predominant role [25]. TGF$\beta 1$ is a multifunctional cytokine, a potent inhibitor of epithelial cell repair, and an inducer of $\mathrm{PF}$ through regulating cell proliferation, growth, differentiation, and movement [26]. Smad family protein is the intracellular transduction molecule of TGF- $\beta$ family reported to be involved in the modulation of cell proliferation and migration [27]. When cells were induced by TGF- $\beta 1$, TGF- $\beta 1$ type I receptor could change its conformation and receptor-regulated Smad proteins were activated by phosphorylation. The phosphorylated Smad3 was released from the receptor. On the contrary, a balanced relationship exists between $\operatorname{Smad} 3$ and $\operatorname{Smad7}$. Smad7 gene is an inhibitory component in the TGF- $\beta 1 /$ Smad signal transduction pathway that can combine with TGF- $\beta 1$ receptor directly and interdict Smad3 activated by the receptor. The response of cells to TGF- $\beta 1$ receded with the increase in gene expression [28]. TGF- $\beta 1$ is the most powerful factor stimulating the transformation of alveolar epithelial cells into interstitial cells, which can promote extracellular matrix deposition and development of PF through inducing EMT [29]. It might serve as a key to block the further development of EMT and reduce PF by interdicting the TGF- $\beta 1 /$ Smad signal transduction pathway effectively. The expression of TGF- $\beta 1 /$ Smad-related proteins was further tested by Western blot. The expression of E-cad and $\alpha$-SMA was close to that in the control group after A549 cells were treated with Tan IIA for $24 \mathrm{~h}$ and EMT was inhibited. Moreover, the effect of Tan IIA on the expression of E-cad and $\alpha$-SMA had a dose-dependent relationship. Furthermore, the expression of Smad3 in A549 cells treated with Tan IIA for $24 \mathrm{~h}$ decreased, but the expression of Smad7 increased. These findings suggested that Tan IIA treatment was able to effectively block the TGF- $\beta 1 /$ Smad signal transduction pathway.

\section{Conclusions}

The present study confirmed that Tan IIA could maintain the stability of cell morphology and prevent the transformation of epithelial cells into fibroblast cells. To some degree, Tan IIA inhibited the EMT phenomenon of alveolar epithelial cells and ameliorated PF induced by TGF- $\beta 1$. The mechanism of Tan IIA inhibiting cell proliferation and EMT might be through the TGF- $\beta 1 /$ Smad signaling pathway. Therefore, Tan IIA might serve as a potential anti-fibrosis drug in treating PF. However, further studies are needed to provide a novel strategy to deliver Tan IIA effectively for PF therapy.

\section{Conflicts of Interest}

The authors declare that there are no conflicts of interest regarding the publication of this study.

\section{Acknowledgment}

This study was subsidized by the Colleges key scientific research project of Henan province (17A310020) and Natural Science Foundation key research projects of Henan province (142102310504).

\section{References}

1. Ying-Ke G, Rui-Qin L,Yu-Wen D. Advances in the study of cytokines in the pathogenesis of pulmonary. AsiaPacific Tradit Med 2016; 12: 69-71.

2. Qing-Mei L, Hai-Yan Ch, Yan-Yun M, Ting W, Feng Q, Xian R, Wen-Zhen T, Xiao-Dong Zh, Li J, Wen-Yu W, Jiu-Cun W. Salvianolic acid b attenuates experimental pulmonary fibrosis through inhibition of the TGF- $\beta$ signaling pathway. Sci Rep 2016; 6: 27610.

3. Pechkovsky DV, Prasse A, Kollert F, Engel KMY, Dentler J, Luttmann W, Friedrich K, Muller-Quermheim J, Zissel $\mathrm{G}$ Alternatively activated alveolar macrophages in pulmonary fibrosis-mediator production and intracellular signal transduction. Clin Immunol 2010; 137: 89-101.

4. Rong L, Fan-Rong L, Quan-Yi X, Chun-Tao L, RongGuang Zh, Cai-Yu P, Tao L, Feng-Qiu X, Qi-Jie L, Yi-Li W. Study on the biological mechanism of chemical fiber formula prescription and moxibustion in preventing pulmonary fibrosis from the perspective of 
transdifferentiation of epithelial cells and mesenchymal cells. J Sichuan Tradit Chinese Med 2012; 30: 45-46.

5. Cichon MA, Nelson CM, Radisky DC. Regulation of epithelial mesenchymal transition in breast cancer cells by cell contact and adhesion. Cancer Informat 2015; 14: $1-13$.

6. Jin-Xin R, Lin-Yan W, Yan D, Yun W, Shuo-Feng Z. Study on model and evaluation index of chronic obstructive pulmonary disease complicated with pulmonary fibrosis. World Sci Technol/Modern Tradit Chinese Med Materia Medica 2013; 15: 1700-1705.

7. Tao Zh, Wei Zh, Min X, Hong-Ying Ch, Hong J. Protective role of andrographolide in bleomycin-induced pulmonary fibrosis in mice. Int $\mathrm{J}$ Mol Sci 2013; 14: 23581-23596.

8. Loomis-King H, Flaherty KR, Moore BB. Pathogenesis, current treatments and future directions for idiopathic pulmonary fibrosis. Curr Opinion Pharmacol 2013; 13: 377-385.

9. Liang ZH, Wei-Wei L, Xun-De W, Yun-Neng T, Jian-Guo S. Glucocorticoid induces mesenchymal-to-epithelial transition and inhibits TGF-B1-induced epithelial-tomesenchymal transition and cell migration. FFBS Letters 2010; 584: 4646-4654.

10. Hisatomi $\mathrm{K}$, Mukae $\mathrm{H}$, Sakamoto N, Ishimatsu $\mathrm{Y}$, Kakugawa T, Hara S, Fujita H, Nakamichi S, Oku H, Urata Y, Kubota H, Nagata K, Kohno S. Pirfenidone inhibits TGF- $\hat{I}^{2} 1$-induced over-expression of collagen type I and heat shock protein 47 in A549 cells. BMC Pulm Med 2012; 12: 24.

11. Ohbayashi M, Kubota S, Kawase A, Kohyama N, Kobayashi Y, Yamamoto T. Involvement of epithelialmesenchymal transition in methotrexate -induced pulmonary fibrosis. J Toxicol Sci 2014; 39: 319-330.

12. Fei ZH, Ying Q, Yong-Hong G, Jun-Hui L, Jie ZH. Effect of Tanshione IIA on proliferation of human renal epithelial and secretion of collagen-induced by TGF-ß1. Shanghai J Tradit Chinese Med 2014; 48: 96-102.

13. Xin L, Chun-Yu G, Xiao-Juan M, Cai-Feng W, Ying Zh, Ming-Yue S, Yu-Ting P, Hui-Jun Y. Anti-Inflammatory effects of Tanshinone IIA on atherosclerostic vessels of ovariectomized ApoE-/-Mice are mediated by estrogen receptor activation and through the ERK signaling pathway. Cell Physiol Biochem 2015; 35: 1744-1755.

14. Dai-Xing ZH, Zhi-Hui L, Cheng-Ye ZH, Li-Wei ZH. Tanshinone IIA inhibits cardiac fibrosis. Chinese J Tissue Eng Res 2013; 17: 3715-3722.

15. Jin-Hui T, Cheng-Ye ZH. Inhibitive effects of Tanshinone IIA on renal interstitial fibrosis in rats. J Apply Clin Pediatr 2009; 24: 392-394.

16. Xiao-Yan Zh, Jin-Xu Zh. Effect of TGF-ß1 induces on human alveolar epithelial cells aboutthe expression of ECad in vitro. Suzhou University J Med Sci 2009; 29: 430-435.

17. Jun-Chao Y, Lu X, Kang S, Yuan W, Run-Di G, Run-Lin $\mathrm{CH}$, Yu C.Effect of Polydatin on epithelial-mesenchymal transition of human alveolar epithelium A549 cells induced by TGF- $\beta 1$. Chinese J Integrated Tradit Western 2016; 36: 466-470.

18. Zhou-Xin R, Hai-Bin Yu, Jian-Sheng Li, Jun-Ling Shen, Wen-Sen D. Biosci Rep 2015; 35: e00202.

19. Wang X, Li L, Huo W, Hou L, Zhao Z, Li W. Characterization and stability of tanshinone IIA solid dispersions with hydroxyapatite. Materials (Basel) 2013; 6: 805-816.

20. Jiang-Feng W, Jian-Guo F, Jing H, Bei-Bei Zh, Wei-Min M. The molecular mechanisms of Tanshinone IIA on the apoptosis and arrest of human esophageal carcinoma cells. BioMed Research Int 2014; 9: 582730.

21. Sheng-Teng H, Chao-Chun H, Wen-Liang H, Tsu-Kung L, Pei-Lin L, Pei-Wen W, Chia-Wei L, Jiin-Haur CH. Tanshinone IIA induces intrinsic apoptosis in osteosarcoma cells both in vivo and in vitro associated with mitochondrial dysfunction. Scientific Rep 2016; 7: 40382.

22. Maitah MY, Ali S, Ahmad A, Gadgeel S, Sarkar FH. Upregulation of sonic hedgehog contributes to TGF-B1induced epithelial to mesenchymal transition in NSCLC Cells. PLoS ONE 2011; 6: e16068.

23. Chai SD, Liu T, Dong MF, Li ZK, Tang PZ, Wang JT, Ma SJ. Inactivated Pseudomonas aeruginosa inhibits hypoxiainduced pulmonary hypertension by preventing TGF- $31 /$ Smad signaling. Brazilian J Med Biol Res 2016; 49: e5526.

24. Gonc, Alves JO, Tannuri ACA, Coelho MCM, Bendit I, Tannuri U. Dynamic expression of desmin, a-SMA and TGF- $\beta 1$ during hepatic fibrogenesis induced by selective bile duct ligation in young rats. Brazilian J Med Biol Res 2014; 47: 850-857.

25. Zhao F, Wang M, Li S, Bai X, Bi H, Liu Y, Ao X, Jia Z, Wu H. DACH1 inhibits SNAI1-mediated epithelialmesenchymal transition and represses breast carcinoma metastasis. Oncogenesis 2015; 4: e143.

26. Chai SD, Liu T, Dong MF, Li ZK, Tang PZ, Wang JT, Ma SJ.Inactivated Pseudomonas aeruginosa inhibits hypoxiainduced pulmonary hypertension by preventing TGF-b1/ Smad signaling. Brazilian J Med Biol Res 2016; 49: e5526.

27. Hu-Zi L, Ai-Jun L, Chun-Li Sh, Bao L. Curcumin suppresses transforming growth factor-beta1-induced cardiac ?suppress differentiation via inhibition of Smad-2 and p38 MAPK signaling pathways. Exp Thera Med 2016; 11: 9985-9946.

28. Jin-Jun D, Chi-Zhi ZH, Hai-Lin X. Gleditsia extract in mice hepatoma cells TGF- $3 /$ Smads regulation of signaling system. Chinese J Integrat Tradit Western Med Liver Dis 2010; 20: 164-165.

29. Zhang L, Ji YX, Jiang WL, Lv CJ. Protective roles of pulmonary rehabilitation mixture in experimental pulmonary fibrosis in vitro and in vivo. Brazilian $\mathrm{J}$ Med Biol Res 2015; 48: 545-552. 


\section{*Correspondence to}

Rui-Qin Li

Scientific Research Pathological Experiment Center

Henan University of Traditional Chinese Medicine

PR China 